\title{
Características produtivas e qualitativas do capim-elefante pastejado em intervalo fixo ou variável de acordo com a interceptação da radiação fotossinteticamente ativa
}

\author{
Tadeu Vinhas Voltolini ${ }^{1}$, Flávio Augusto Portela Santos ${ }^{2}$, Junio Cesar Martinez ${ }^{3}$, Rafael Luis \\ Clarindo ${ }^{3}$, Marco Antonio Penati ${ }^{4}$, Hugo Imaizumi ${ }^{3}$ \\ ${ }^{1}$ Pós-graduação em Ciência Animal - Escola Superior de Agricultura "Luiz de Queiroz", Universidade de São Paulo, Piracicaba, SP; Embrapa \\ Semiárido, Petrolina, PE. \\ 2 Departamento de Zootecnia da Escola Superior de Agricultura "Luiz de Queiroz", Universidade de São Paulo, Piracicaba, SP. \\ 3 Pós-graduação em Ciência Animal - Escola Superior de Agricultura "Luiz de Queiroz", Universidade de São Paulo, Piracicaba, SP. \\ ${ }^{4}$ Escola Superior de Agricultura "Luiz de Queiroz", Universidade de São Paulo, Piracicaba, SP.
}

RESUMO - Objetivou-se avaliar dois intervalos de pastejo de pastos de capim-elefante (Pennisetum purpureum Schum.): um intervalo variável, quando o dossel atingisse $95 \%$ de interceptação da radiação fotossinteticamente ativa, e um intervalo de pastejo fixo, de 26 dias. O delineamento experimental foi o inteiramente casualizado com medidas repetidas no tempo. O intervalo de pastejo, a altura do dossel no pré e pós-pastejo, a interceptação da radiação fotossinteticamente ativa e o índice de área foliar foram maiores quando aplicado o intervalo de pastejo fixo. Não houve efeito dos intervalos de pastejo sobre as massas de forragem, de folhas e de colmos no pré e pós-pastejo nem sobre a densidade volumétrica do dossel no pré-pastejo. A massa de material morto foi menor no intervalo de pastejo variável em comparação ao intervalo fixo, tanto no pré quanto no pós-pastejo. Os teores de fibra em detergente neutro e fibra em detergente ácido nos pastos manejados em intervalo variável foram menores que naquela com intervalo fixo. A aplicação de intervalo de pastejo variável, por permitir redução do tempo de descanso do pasto, tem efeitos positivos na qualidade da forragem.

Palavras-chave: interceptação de luz, lotação rotacionada, manejo do pastejo, Pennisetum purpureum, período de descanso, valor nutritivo

\section{Productive and qualitative characteristics of elephant grass pasture grazed in fixed and intermittent intervals according to interception of active photosynthetic radiation}

\begin{abstract}
The objective of this trial was to evaluate two intervals of grazing on elephant grass (Pennisetum purpureum Schum.) pasture. It was tested a variable grazing interval when it was observed an interception of $95 \%$ of active photosynthetic radiation by sward, and a 26-day fixed grazing interval. The experimental design was a complete randomized design with time repeated measurements. The interval of grazing, pre and post grazing sward heights, sward interception of active photosynthetic radiation and leaf area index were greater when the fixed pasture interval was applied. There was no effect of intervals of grazing on forage mass, leaf mass and stem mass in pre- or post-grazing neither for sward volumetric density in pre grazing. Dead material mass was lower for variable grazing interval than in fixzed grazing for both pre and post grazing. Neutral detergent fiber and acid detergent fiber contents were lower in the grazing managed in the variable interval than in the fixed grazing interval. The use of variable grazing interval intervals that promoted reduction in resting time of the pasture resulted in positive effects on forage quality.
\end{abstract}

Key Words: chemical composition, interval between grazing, light interception, pasture management, Pennisetum purpureum, rotational grazing

\section{Introdução}

O crescimento da planta forrageira é determinado pelas condições genéticas e ambientais (fertilidade do solo, características climáticas, etc), que podem potencializar ou limitar a produção de forrragem.

Assim, o estabelecimento do ciclo de pastejo em dias fixos pode promover a desfolha precoce ou tardia do

Recebido em 22/3/2007 e aprovado em 28/4/2009.

Correspondências devem ser enviadas para: tadeu.voltolini@cpatsa.embrapa.br 
dossel forrageiro (Carnevalli et al., 2006; Voltolini et al., 2010), dependendo das condições experimentadas pela planta durante o período de descanso. Isso pode prejudicar a produção, a qualidade e a eficiência de colheita da forragem pelos animais em pastejo (Cândido et al., 2005).

Esses prejuízos são decorrentes da menor produção de matéria seca (MS), acarretada por colheitas precoces da forragem, prejudicando o crescimento da planta ou do acúmulo de colmos e material morto, como consequência de pastejos tardios.

Segundo Carnevalli et al. (2006), a adoção de intervalos de pastejos variáveis é uma estratégia eficiente para definir a frequência de pastejo das gramíneas forrageiras tropicais. Essa proposta baseia-se nas fortes influências dos fatores ambientais sobre o crescimento das plantas forrageiras, determinando a dinâmica de crescimento da planta e o melhor momento para o pastejo.

Em estudos conduzidos por Gomide et al. (2007) e Barbosa et al. (2007) em capim-tanzânia em diferentes intervalos de pastejo, definidos pelo número de folhas vivas por perfilho ou pela interceptação da radiação fotossinteticamente ativa, respectivamente, foram observados prejuízos na estrutura do dossel forrageiro com o prolongamento do intervalo de pastejo. Pedreira et al. (2007), por sua vez, avaliaram três frequências de desfolha (95 e 100\% de interceptação da radiação fotossinteticamente ativa e intervalo fixo de 28 dias) para o capim-braquiária (Brachiaria brizantha cv. Xaraés) e observaram maior acúmulo total de matéria seca, além de maiores acúmulos de colmos e material morto no resíduo pós-pastejo no período de descanso de $100 \%$ de interceptação de radiação fotossinteticamente ativa.

São escassas informações para a definição do período de descanso do capim-elefante, uma das mais importantes gramíneas forrageiras tropicais. Assim, realizou-se este trabalho com o objetivo de avaliar os parâmetros produtivos e qualitativos do capim-elefante pastejado por vacas em lactação em intervalos fixos ou variáveis, de acordo com a interceptação da radiação fotossinteticamente ativa.

\section{Material e Métodos}

O ensaio foi conduzido no sistema de produção de leite do Centro de Treinamento de Recursos Humanos (CTRH), do Departamento de Zootecnia da USP/ESALQ, no município de Piracicaba - São Paulo. As coordenadas geográficas do município de Piracicaba são: 22 43' de latitude Sul, 47 25' de longitude Oeste e 580 m de altitude.

Foram utilizados 2,8 hectares de pastagem de capimelefante (Pennisetum purpureum Schum. cv. Cameroon), divididos em 56 piquetes de 0,05 ha. Para cada intervalo de pastejo testado, foram disponibilizados 28 piquetes. Os dois intervalos de pastejo experimentais foram distribuídos aleatoriamente na área experimental. Os piquetes foram roçados e começaram a ser pastejados em meados de novembro de 2003, observando períodos de descanso de 26 dias até o início do período experimental.

O delineamento experimental utilizado foi o inteiramente casualizado com medidas repetidas no tempo (quatro subperíodos) e dois intervalos de pastejo. O período experimental teve início em fevereiro de 2004 e estendeu-se até abril do mesmo ano, com duração de 80 dias, dividido em quatro subperíodos de 20 dias. As respectivas datas para cada subperíodo foram: 3 a 23 de fevereiro (subperíodo 1); 24 de fevereiro a 17 de março (subperíodo 2); 18 de março a 3 de abril (subperíodo 3); e 4 a 27 de abril (subperíodo 4).

Durante o período experimental, foram observados os dados climáticos (Tabela 1) e realizadas análises químicas de macronutrientes do solo da área experimental, cujos resultados foram: potencial hidrogeniônico em $\mathrm{CaCl}_{2}=$ 5,6; matéria orgânica $=37 \mathrm{~g} / \mathrm{dm}^{3}$; fósforo $=30,3 \mathrm{mg} / \mathrm{dm}^{3}$; potássio $=7,07 \mathrm{Mmol} / \mathrm{dm}^{3} ;$ cálcio $=47 \mathrm{Mmol} / \mathrm{dm}^{3} ;$ magnésio = $28 \mathrm{Mmol} / \mathrm{dm}^{3}$; alumínio = $0 \mathrm{Mmol} / \mathrm{dm}^{3}$; hidrogênio + alumínio = $20 \mathrm{Mmol} / \mathrm{dm}^{3}$; soma de bases = 82,3 Mmol $/ \mathrm{dm}^{3}$; capacidade de troca catiônica $=\mathrm{Mmol} / \mathrm{dm}^{3}$; saturação de bases $=80,3 \%$ e saturação por alumínio $=0 \%$. Já os resultados das análises de micronutrientes do solo foram: boro $=0,58 \mathrm{mg} / \mathrm{dm}^{3}$; cobre $=7,8 \mathrm{mg} / \mathrm{dm}^{3}$; ferro $=40 \mathrm{mg} / \mathrm{dm}^{3}$; manganês $=60,6 \mathrm{mg} / \mathrm{dm}^{3} ;$ zinco $=6,4 \mathrm{mg} / \mathrm{dm}^{3}$.

Tabela 1 - Dados climáticos observados durante a condução do ensaio experimental

\begin{tabular}{|c|c|c|c|c|c|c|c|c|}
\hline \multirow[t]{2}{*}{ Mês } & \multicolumn{3}{|c|}{$\begin{array}{c}\text { Temperatura } \\
\left({ }^{\circ} \mathrm{C}\right)\end{array}$} & \multicolumn{3}{|c|}{$\begin{array}{c}\text { Umidade relativa } \\
(\%)\end{array}$} & \multirow{2}{*}{$\begin{array}{c}\text { Precipitação } \\
\text { total } \\
(\mathrm{mm})\end{array}$} & \multirow{2}{*}{$\begin{array}{c}\text { Radiação } \\
\text { solar total } \\
\left(\mathrm{MJ} / \mathrm{m}^{2}\right)\end{array}$} \\
\hline & Média & Mínima & Máxima & Média & Mínima & Máxima & & \\
\hline Janeiro/2004 & 22,8 & 18,7 & 28,9 & 81,1 & 53,9 & 97,3 & 214,3 & 17,6 \\
\hline Fevereiro/2004 & 22,8 & 18,2 & 29,2 & 80,2 & 52,1 & 97,8 & 193,7 & 18,9 \\
\hline Março/2004 & 22,4 & 17,3 & 29,2 & 78,3 & 46,9 & 98,9 & 79,0 & 19,2 \\
\hline Abril/2004 & 22,0 & 16,9 & 28,6 & 80,9 & 50,8 & 99,6 & 87,7 & 15,8 \\
\hline
\end{tabular}

Fonte: Estação meteorológica automática da USP/ESALQ. 
Foram avaliados dois intervalos de pastejo, sendo a entrada dos animais nos piquetes quando estes apresentassem 95\% de interceptação da radiação fotossinteticamente ativa; e outro com intervalo de pastejo fixo de 26 dias. O período de ocupação dos piquetes foi de um dia pelas vacas lactantes e um dia pelos animais de repasse, perfazendo no total dois dias de ocupação.

Para medir a interceptação da radiação fotossinteticamente ativa e o índice de área foliar do dossel, foi utilizado equipamento da marca LI-COR modelo LAI 2000 (LI-COR, Lincoln, Nebraska, EUA).

Nos primeiros 17 dias de cada subperíodo, a radiação fotossinteticamente ativa foi medida em aproximadamente $60 \%$ dos dias. Dessa maneira, alguns dos piquetes do intervalo variável, foram pastejados de acordo com a avaliação visual.

Nos últimos três dias dos subperíodos, o monitoramento da interceptação da RFA foi efetuado diariamente nos piquetes de ambos os intervalos de pastejo. No intervalo fixo de pastejo, apenas o piquete determinado para ser pastejado foi monitorado antes da entrada dos animais. Nos piquetes do intervalo de pastejo variável, os três piquetes com a maior massa de forragem acumulada visualmente foram avaliados para que fosse utilizado o que estivesse com valor mais próximo de 95\% de interceptação de RFA. Em cada piquete foram realizadas 20 leituras de RFA, no nível do solo. Os piquetes com valores superiores a 95\% de interceptação da RFA foram pastejados por animais não experimentais.

Com base na análise de solo, as áreas foram adubadas apenas com fonte nitrogenada (nitrato de amônia). A dose aplicada desde a roçada até o final do experimento foi de $2 \mathrm{~kg}$ de nitrogênio/ha por dia de intervalo de pastejo. Dessa forma, se um piquete do intervalo de pastejo variável apresentasse 95\% de interceptação da RFA em 26 dias, a dose de nitrogênio $(\mathrm{N})$ a ser aplicada na saída dos animais era equivalente a $52 \mathrm{~kg}$ de $\mathrm{N} / \mathrm{ha}$, enquanto que, no intervalo fixo, a dose aplicada era sempre o equivalente a $52 \mathrm{~kg}$ de nitrogênio/ha.

Foram utilizadas oito vacas holandesas lactantes como animais-testadores e número variável de vacas reguladoras, para ajuste da taxa de lotação. Vacas não lactantes e animais em crescimento foram utilizados para a realização do repasse pós-pastejo, quando necessário. Os animais-testadores receberam suplementação com 6,3 kg de MS/dia de concentrado contendo 18\% de proteína bruta (PB) e $72 \%$ de nutrientes digestíveis totais, parcelado em dois fornecimentos diários.

A taxa de lotação foi ajustada diariamente, à entrada de cada piquete. A oferta de forragem foi estabelecida em $4 \mathrm{~kg}$ de matéria seca para $100 \mathrm{~kg}$ de peso corporal por dia, considerando a massa de forragem obtida com corte feito acima do resíduo pós-pastejo do ciclo anterior.

As medidas quantitativas da pastagem foram: as massas de forragem no pré e pós-pastejo, realizando a colheita da forragem com corte rente ao solo. Para a coleta das amostras, foi utilizada moldura em formato quadrado $\left(1 \mathrm{~m}^{2}\right)$. Foram coletadas duas amostras aleatórias em pré e pós-pastejo de cada um dos três piquetes pastejados de cada intervalo de pastejo, durante os três dias do período de coleta em cada um dos quatro subperíodos experimentais. Dos 28 piquetes de cada tratamento, alguns foram amostrados mais de uma vez enquanto outros não foram amostrados, em função das datas de coleta e rotação dos piquetes.

Em cada piquete, foram também colhidas duas amostras de massa de forragem ( $1 \mathrm{~m}^{2}$ e moldura em formato quadrado) para ajuste da taxa de lotação.

As avaliações qualitativas foram: interceptação da RFA, altura do dossel no pré e pós-pastejo, densidade volumétrica, IAF e composição morfológica do pré e pós-pastejo e composição bromatológica do pastejo simulado.

O pastejo simulado para os dois intervalos de pastejo foi obtido por meio da colheita manual da forragem na altura média do resíduo pós-pastejo em 20 pontos de cada piquete pastejado durante cada período de coleta.

A composição morfológica foi avaliada a partir de uma subfração (aproximadamente $300 \mathrm{~g}$ ) das amostras de massa de forragem (corte rente ao solo) no pré e pós-pastejo. Foram separadas as folhas (apenas as lâminas foliares), colmos (bainha + colmo) e o material morto (folhas ou colmos com mais de $50 \%$ da área seca). As amostras de folhas, colmos e material morto foram pesadas in natura e levadas a estufa de ventilação forçada e mantidas por 48 horas a $55^{\circ} \mathrm{C}$ para a quantificação do peso seco.

A densidade volumétrica do dossel foi determinada por meio da relação entre a massa de forragem e a altura no pré-pastejo. O valor de densidade volumétrica foi obtido a partir da massa de forragem cortada na altura do resíduo pós-pastejo do ciclo anterior.

A altura foi medida como o comprimento, desde o nível do solo até a curvatura da última folha completamente expandida, utilizando-se uma régua de madeira de 2,50 m de comprimento, graduada em centímetros. Foram tomadas 20 medidas por piquete durante o período de coleta no pré e pós-pastejo.

As amostras de forragem (pastejo simulado e frações da planta inteira) foram levadas à estufa de circulação forçada de ar, mantidas a $55^{\circ} \mathrm{C}$ por 48 horas e processadas 
em moinhos tipo Willey em peneiras com malhas de $5 \mathrm{~mm}$ e posteriormente de $1 \mathrm{~mm}$.

Após a pré-secagem, as frações (folha, colmo e material morto), foram encaminhadas para a secagem definitiva (AOAC, 1975). As amostras de pastejo simulado foram analisadas quanto aos teores de matéria seca; matéria orgânica, extrato etéreo e proteína bruta (AOAC, 1975). As análises de fibra em detergente neutro (FDN), fibra em detergente ácido (FDA) e lignina foram efetuadas de acordo com Goering \& Van Soest (1970).

Os dados referentes às variáveis analisadas foram submetidos ao PROC MIXED do Statystical Analyses System - SAS (1999). Considerando como efeito significativo o nível de até $5 \%$ de probabilidade $(\mathrm{P}<0,05)$. As médias foram obtidas utilizando-se o método dos quadrados mínimos (Lsmeans).

\section{Resultados e Discussão}

A interceptação da RFA diferiu $(\mathrm{P}<0,05)$ entre os intervalos de pastejo. O valor médio observado foi de 95,5\%, muito próximo do objetivo de 95\% estabelecido como o ponto para a entrada dos animais na área de pastagem do intervalo de pastejo variável. A adoção de intervalo fixo de pastejo de 26 dias (IPF26) resultou em valor médio de interceptação de RFA de 97,91\% (Tabela 2).

O intervalo de pastejo, altura do dossel no pré e póspastejo e o IAF foram afetados pelos intervalos de pastejo $(\mathrm{P}<0,05)$. Não foram observados efeitos dos intervalos de pastejo $(\mathrm{P}<0,05)$ sobre a densidade volumétrica do dossel.

A estratégia de entrada no piquete quando este atingiu interceptação de 95\% de RFA (RFA95) resultou em intervalo médio de pastejo de 19,4 dias. Este valor foi significativamente menor $(\mathrm{P}<0,05)$ que os 26 dias fixos do intervalo fixo.

Esse comportamento foi semelhante aos reportados por Carnevalli et al. (2006), que observaram intervalos de pastejo de 23 a 25 dias para o capim-mombaça, com 95\% de interceptação da RFA e dois resíduos pós-pastejo (30 e $50 \mathrm{~cm}$ ) durante a estação das águas e por Pedreira et al. (2007) que avaliaram três intervalos de pastejo (95\% e 100\% de interceptação da RFA e 28 dias fixos) de pastagens de capim-braquiária cv. Xaraés e encontraram períodos de descanso de 22; 27,7 e 31,7 dias, respectivamente.

Mello \& Pedreira (2004) observaram que, para o capimtanzânia atingir 95\% de interceptação de RFA, foram necessários 22 dias de descanso. Em adição, Moreno (2004) observou valores de interceptação de RFA de 95,0 a 98,0\% durante o verão para máximas taxas de acúmulo em cinco gramíneas do gênero Panicum. Os intervalos de cortes variaram de 28 a 35 dias.

Tanto Mello \& Pedreira (2004) quanto Pedreira et al. (2007) apontam a redução no intervalo de pastejo como importante ferramenta para melhorar a composição morfológica e estrutural da planta forrageira. Esse fato sugere o uso de menores intervalos de pastejo para o capimelefante durante a estação das águas em relação aos usados tradicionalment,e que variam de 30 a 45 dias.

Houve interação intervalo de pastejo $\times$ subperíodo para os intervalos de pastejo $(\mathrm{P}<0,05)$ (Tabela 3$)$. O intervalo de pastejo variável variou entre os subperíodos. O intervalo mínimo de pastejo no RFA95 foi de 17,3 dias no subperíodo 1 e o máximo, de 21 dias no subperíodo 4. Possivelmente, os maiores índices pluviométricos obtidos nos meses de janeiro (subperíodo 1) associado aos maiores valores de radiação solar total em relação ao subperíodo 4 (Tabela 1) podem justificar tais resultados. Os valores observados para o intervalo de pastejo variável foram sempre inferiores $(\mathrm{P}<0,05)$ aos 26 dias fixos do IPF26.

Considerando a recomendação de entrada dos animais no piquete quando este atinge interceptação de $95 \%$ de RFA (Da Silva, 2005), em solos com alta fertilidade como os do presente estudo, o capim-elefante precisa ser manejado com intervalo de pastejo bastante freqüente durante o período de verão. Os intervalos de pastejo na pastagem manejada a 95\% da radiação fotossinteticamente

Tabela 2 - Interceptação da radiação fotossinteticamente ativa (RFA), intervalo de pastejo, alturas em pré e pós-pastejo, densidade volumétrica e índice de área foliar do dossel de pastagens de capim-elefante submetidas a dois intervalos de pastejos

\begin{tabular}{lccr}
\hline Componente & Intervalos de pastejo & \multicolumn{2}{c}{$\mathrm{EPM}^{2}$} \\
\cline { 2 - 3 } & Variável & Fixo & 0,0001 \\
Interceptação da RFA (\%) & $95,5 \mathrm{a}$ & $97,9 \mathrm{~b}$ & 0,17 \\
Intervalo de pastejo (dias) & $19,4 \mathrm{a}$ & $26,0 \mathrm{~b}$ & 0,25 \\
Altura do dossel pré pastejo (m) & $1,03 \mathrm{a}$ & 0,0001 \\
Altura do dossel pós-pastejo (m) & $0,62 \mathrm{a}$ & 0,0001 \\
Densidade volumétrica (kg de MS/ha/cm) & 63,3 & 0,02 & 0,01 \\
Índice de área foliar (pontos) & $3,80 \mathrm{a}$ & 53,3 & 0,10 \\
\hline
\end{tabular}

Na linha, médias seguidas de letras minúsculas diferentes variam $(\mathrm{P}<0,05)$ pelo teste de Tukey. RFA95 = intervalo de pastejo determinado pela interceptação de $95 \%$ da radiação fotossinteticamente ativa; IPF26 = intervalo de pastejo fixo de 26 dias; 1 = Probabilidade; 2 = Erro-padrão da média. 
ativa foram menores que os 22 dias relatados por Mello \& Pedreira (2004) com capim-tanzânia e os 23 a 25 dias relatados por Carnevalli et al. (2006), para o capim-mombaça, com 95\% de interceptação de RFA e dois resíduos pós pastejo (30 e $50 \mathrm{~cm}$ ), durante a estação das águas.

As alturas dos dosséis no pré e pós-pastejo também reduziram $(\mathrm{P}<0,05)$ com a estratégia de entrada nos piquetes do intervalo de pastejo variável em comparação com à entrada com base em dias fixos. Carnevalli et al. (2006) observaram o mesmo comportamento no capim-mombaça.

Pedreira et al. (2007) também observaram menor altura do dossel de capim-braquiária cv. Xaraés, em pré-pastejo, com o uso de 95\% de interceptação da RFA em comparação ao intervalo de $100 \%$ de interceptação ou 28 dias fixos.

Os valores de altura encontrados neste ensaio são inferiores aos utilizados freqüentemente no manejo do capim-elefante,em torno de 1,5 a 2,0 m no pré e 0,7 a 1,0 m no pós-pastejo (Deresz et al., 2001).

As alterações na altura do dossel no pré e pós-pastejo podem levar a mudanças na composição morfológica e estrutural da planta forrageira, as quais podem contribuir para o aumento do consumo de forragem (Da Silva, 2005). A redução na altura do dossel no pré e pós-pastejo é condição primordial para aumentar a eficiência de utilização do capim-elefante, devido principalmente à redução nas perdas durante o pastejo.

Não houve interação intervalo de pastejo $x$ subperíodo para a altura do dossel pré-pastejo $(\mathrm{P}>0,05)$. No intervalo de pastejo variável, não houve variação na altura do dossel $(\mathrm{P}>0,05)$ quando a planta atingiu interceptação de 95\% de RFA entre os quatros subperíodos. Já no intervalo de pastejo fixo, houve variação na altura do dossel $(\mathrm{P}<0,05)$. O menor valor médio foi de $1,15 \mathrm{~m}$ no subperíodo 3 e o maior valor médio, de 1,26m no subperíodo 2. Apesar disso, houve grande uniformidade entre os valores de altura pré-pastejo dos subperíodos 1 , 2 e 4 do intervalo fixo de pastejo. Provavelmente, as boas condições climáticas, caracterizadas pelos índices de precipitação

Tabela 3 - Intervalo médio de pastejo em pastagens de capimelefante pastejado por vacas em lactação durante quatro subperíodos

\begin{tabular}{|c|c|c|c|c|}
\hline \multirow[t]{2}{*}{ Subperíodo } & \multicolumn{2}{|c|}{ Intervalo de pastejo (dias) } & \multirow[t]{2}{*}{ EPM2 } & \multirow[t]{2}{*}{$\mathrm{P} 1$} \\
\hline & Variável & Fixo & & \\
\hline 1 & $17,3 \mathrm{a}$ & $26,0 \mathrm{~b}$ & 0,66 & 0,001 \\
\hline 2 & $20,7 a$ & $26,0 \mathrm{~b}$ & 0,66 & 0,001 \\
\hline 3 & $19,3 \mathrm{a}$ & $26,0 \mathrm{~b}$ & 0,66 & 0,001 \\
\hline 4 & $21,0 \mathrm{a}$ & $26,0 \mathrm{~b}$ & 0,66 & 0,001 \\
\hline Média & 19,4 & 26,0 & 0,25 & - \\
\hline
\end{tabular}

Na linha, médias seguidas de diferentes letras minúsculas são diferentes $(\mathrm{P}<0,05)$ pelo teste de Tukey. ${ }^{1}$ Probabilidade; ${ }^{2}$ Erro- padrão da média, $\mathrm{P}>0,05=$ interação entre intervalo de pastejo e subperíodo. pluviométrica e radiação solar total durante o período experimental possibilitaram a obtenção desses resultados.

Durante todo o período experimental, a altura em prépastejo do dossel forrageiro no intervalo fixo foi numericamente superior ao intervalo de pastejo variável.

Houve interação intervalo de pastejo $\times$ subperíodo para a altura do dossel pós-pastejo $(\mathrm{P}<0,05)$ (Tabela 4$)$. No subperíodo 1 não foi observada diferença $(\mathrm{P}>0,05)$ entre os intervalos de pastejo, já nos outros três subperíodos foram observados menores valores $(\mathrm{P}<0,05)$ para o intervalo de pastejo variável. As avaliações das características qualitativas e quantitativas da pastagem em cada subperíodo ocorreu em vários piquetes, o que justifica essas variações ao longo do estudo. Além disso, o intervalo de pastejo de 26 dias pode ter possibilitado a elevação da altura do dossel no pós-pastejo com a sucessão de pastejos em virtude da maior altura do dossel em pré-pastejo.

O intervalo de pastejo variável foi eficaz na manutenção da altura pós-pastejo durante os quatros subperíodos avaliados, mesmo com fortes influências do manejo préexperimental com 26 dias fixos. No intervalo fixo de 26 dias entre pastejos, a altura do resíduo pós-pastejo aumentou do subperíodo 1 (0,66 m) para o subperíodo 4 (0,79 m).

O controle da altura do resíduo pós-pastejo tem sido uma das maiores dificuldades no manejo de capim-elefante em diversas propriedades rurais. A adoção do intervalo variável de pastejo, com base na interceptação de 95\% da RFA permitiu controle mais eficiente do resíduo póspastejo em três dos subperíodos.

Tanto Pedreira et al. (2007) quanto Barbosa et al. (2007), que trabalharam , respectivamente, com capim-braquiária cv. Xaraés e capim-mombaça, relataram que houve estabilidade dos valores de altura dos dosséis durante todo o período de avaliação em relação às interceptações de RFA. Esse fato indica que a altura em pré-pastejo pode ser utilizada como parâmetro prático e eficiente da interceptação da RFA e do manejo do pastejo de gramíneas forrageiras tropicais.

Tabela 4 - Altura do resíduo pós-pastejo de pastagens de capimelefante em quatro subperíodos

\begin{tabular}{|c|c|c|c|c|}
\hline \multirow[t]{2}{*}{ Subperíodo } & \multicolumn{2}{|c|}{ Intervalo de pastejo (m) } & \multirow[t]{2}{*}{ EPM 2} & \multirow[t]{2}{*}{$\mathrm{P} 1$} \\
\hline & Variável & Fixo & & \\
\hline 1 & 0,72 & 0,62 & 0,05 & 0,26 \\
\hline 2 & $0,53 a$ & $0,63 b$ & 0,05 & 0,03 \\
\hline 3 & $0,54 \mathrm{a}$ & $0,72 b$ & 0,05 & 0,002 \\
\hline 4 & $0,62 \mathrm{a}$ & $0,79 b$ & 0,05 & 0,004 \\
\hline Média & 0,62 & 0,71 & 0,02 & - \\
\hline
\end{tabular}

Na linha, médias seguidas de diferentes letras minúsculas são diferentes $(\mathrm{P}<0,05)$ pelo teste de Tukey. ${ }^{1}$ Probabilidade; ${ }^{2}$ Erro- padrão da média, $\mathrm{P}<0,05$ interação entre intervalo de pastejo e subperíodo. 
Não houve efeito dos intervalos de pastejo ( $\mathrm{P}>0,05)$ sobre a densidade volumétrica do dossel forrageiro. Os valores observados foram inferiores à variação de 65 a $98 \mathrm{~kg}$ de MS/ha/cm reportados por Voltolini et al. (2008), também com capim-elefante. No entanto, para o cálculo da densidade volumétrica neste estudo, foi utilizada a forragem colhida acima do nível do resíduo pós-pastejo composta em quase sua totalidade por folhas.

O índice de área foliar na pastagem manejada em intervalo fixo de pastejo foi maior $(\mathrm{P}<0,05)$ que naquela com intervalo variável. Pedreira et al. (2007) também não observaram variáveis no IAF entre o intervalo de 95\% de interceptação da RFA em comparaçãoao de 28 dias fixos no capimbraquiária cv. Xaraés. Entretanto, esses autores observaram diferenças no IAF entre os intervalos de pastejo.

Os intervalos de pastejo não afetaram $(\mathrm{P}>0,05)$ as massas de forragem no pré e pós-pastejo (Tabela 5). A redução no intervalo de pastejo permite aumentar o número de ciclos de pastejo, o que pode contribuir para a produção total de matéria seca durante toda a estação das águas. Nos 80 dias de período experimental, o intervalo médio de pastejo de 19,4 dias no intervalo de pastejo variável permitiu 4,12 ciclos de pastejo contra 2,96 ciclos com o intervalo fixo de 26 dias.

Em avaliações do capim-mombaça, Carnevalli et al. (2006), verificaram que o intervalo de pastejo com $95 \%$ de interceptação da RFA permitiu oito ciclos de pastejo, enquanto com $100 \%$ de interceptação de RFA pelo dossel foram realizados aproximadamente seis ciclos de pastejo durante todo o ano.

Em estudo realizado por Barbosa et al. (2007) com o capim-tanzânia submetido a três frequências (90\%; 95\% e $100 \%$ de interceptação da RFA) e duas intensidades de pastejo (25 e $30 \mathrm{~cm}$ de resíduo pós-pastejo), o número de ciclos de pastejo para as três interceptações de RFA, respectivamente, foram de 6; 5 e 3 para o resíduo póspastejo de 25 cm e 7; 6 e 4 para o resíduo pós-pastejo de 50 cm. Pedreira et al. (2007) trabalharam com o capim-braquiária cv. Xaraés e observaram maior número de ciclos de pastejo no intervalo de pastejo com 95\% de interceptação da RFA, seguido pelos intervalos de pastejo com 28 dias fixos e $100 \%$ de interceptação da RFA.

Os valores observados para a massa de forragem em pré-pastejo de 6.270 e $6.310 \mathrm{~kg}$ de MS/ha denotam alta capacidade de acúmulo de forragem do capim-elefante em sistemas intensivos de pastejo.

Aroeira et al. (2001) avaliaram a massa de forragem de pastagens de capim-elefante em diferentes intervalos de pastejos (30, 37,5 e 45 dias) e observaram maiores valores no intervalo de 45 dias. Por outro lado, Deresz (2001) e Deresz et al. (2001) não observaram efeitos do uso de intervalos de pastejos (30, 36, 45 dias e 30 e 45 dias, respectivamente) sobre a massa de forragem pré-pastejo de pastagens de capim-elefante. Wendling et al. (2004) avaliaram as respostas quantitativas e qualitativas de pastagens de capim-elefante em dois intervalos de pastejo (24 e 30 dias) e também não observaram efeito dos intervalos de pastejo sobre as massas de forragem em pré-pastejo.

Os valores de massa de forragem em pré-pastejo desse estudo foram menores que os obtidos por Voltolini et al. (2008), na mesma área experimental. Esses autores relataram valores de 8.000 a $16.000 \mathrm{~kg}$ MS/ha por ciclo de pastejo. Entretanto, trabalharam com períodos de descanso de 38 a 40 dias. As massas de forragem dos resíduos pós-pastejo nesses trabalhos foram excessivamente altas, variando de 6.000 a $10.700 \mathrm{~kg}$ de MS/ha, compostos principalmente por colmos e material morto, enqaunto neste estudo foram 3.580 a $3.850 \mathrm{~kg}$ MS/ha.

Apesar de as massas de forragem pré-pastejo observadas nos estudos de Voltolini et al. (2008) terem sido superiores a deste estudo, a massa de folhas foi semelhante, o que indica alta participação de colmos e material morto com períodos de descanso de 38 a 40 dias.

Apesar de taxa de acúmulo de forragem não ter sido calculada, a produção de forragem foi maior no intervalo de pastejo variável, uma vez que a massa de forragem prépastejo foi igual nos dois intervalos de pastejo, porém, com intervalo de pastejo de 19,4 dias para o RFA95 contra 26 dias para o IPF26.

A maior taxa de acúmulo de forragem com menor intervalo de pastejo, também foi relatada por Barbosa et al. (2007), em pesquisa com capim-mombaça. No estudo de Barbosa et al. (2007), foram observadas maiores taxas de acúmulo de forragem quando adotado intervalo de pastejo com interceptação de 95\% de RFA associado ao resíduo pós-pastejo de 25 cm, em comparação à interceptação de 90 ou $100 \%$ de RFA e resíduos pós-pastejo de $50 \mathrm{~cm}$.

Tabela 5 - Massa de forragem em pré e pós-pastejo de pastagens de capim-elefante submetidas a dois intervalos de pastejo

\begin{tabular}{lccc}
\hline Componente & \multicolumn{2}{c}{ Intervalos de pastejo } & \multirow{2}{*}{$\mathrm{EPM}^{2}$} \\
\cline { 2 - 3 } & Variável & Fixo & \\
\hline Massa de forragem pré-pastejo (kg de MS/ha) & 6.270 & 6.310 & 490 \\
Massa de forragem pós-pastejo (kg de MS/ha) & 3.580 & 3.850 & 350 \\
\hline
\end{tabular}

${ }^{1}$ Probabilidade; ${ }^{2}$ Erro-padrão da média. 
Não houve interação intervalo de pastejo $\times$ subperíodo $(\mathrm{P}>0,05)$ para a massa de forragem pré e pós-pastejo. Com a precipitação pluviométrica adequada nos meses de janeiro e fevereiro (Tabela 1), os valores de massa de forragem prépastejo foram altos e uniformes nos subperíodos 1 a 4 nos dois intervalos de pastejo.

As quantidades de massa de forragem pós-pastejo não variaram entre os intervalos de pastejo nem entre os subperíodos. A diferença na altura do resíduo pós-pastejo entre os intervalos de pastejo não refletiu na massa de forragem residual.

Não houve interação intervalo de pastejo $\times$ subperíodo ( $\mathrm{P}>0,05)$ para a composição morfológica tanto no pré quanto no pós-pastejo. Os intervalos de pastejo não afetaram $(\mathrm{P}>0,05)$ as massas de folhas no pré e pós-pastejo. Houve maior $(\mathrm{P}<0,05)$ massa de material morto no intervalo fixo de pastejo, tanto no pré quanto no pós-pastejo (Tabela 6).

No trabalho de Carnevalli et al. (2006), a proporção de folhas em pastagem de capim-mombaça durante o verão não diferiu entre os intervalos de pastejo fixo e variável. Neste estudo, no intervalo fixo entre pastejos de 26 dias, a interceptação da radiação fotossinteticamente ativa não atingiu 100\%, o valor de interceptação foi de 97,9\%.

Os resultados observados para a massa de material morto em pré-pastejo contrastam com os obtidos por Carnevalli et al. (2006), que não observaram diferença na proporção de material morto em pastagens de capimmombaça em rebrotação e manejadas com intervalos de pastejo determinados pela interceptação de $95 \%$ ou $100 \%$ da RFA no verão.

Da mesma forma, Pedreira et al. (2007) não encontraram diferenças na massa de material morto de pastagens de capim-braquiária cv. Xaraés com três estratégias de manejo (95 e 100\% de interceptação de RFA e 28 dias fixos) no último ciclo de pastejo.

Entretanto, em pastagens de capim-mombaça, Barbosa et al. (2007) observaram maior acúmulo de material morto e colmos na massa de forragem em pré-pastejo com o intervalo de $100 \%$ de interceptação de RFA em comparação à interceptação de 95\% de RFA, enquanto Carnevalli et al. (2006) observaram maior proporção de material morto no resíduo pós-pastejo, o que está de acordo com os resultados obtidos neste estudo.

Além da redução na altura do resíduo pós-pastejo no intervalo de pastejo variável em comparação intervalo fixo de pastejo, a qualidade do resíduo também foi melhor no intervalo variável, pois houve menor massa de material morto.

Carnevalli et al. (2006) observaram maior proporção de folhas no resíduo pós-pastejo de capim-mombaça pastejado com interceptação de 95\% da RFA em comparação à interceptação de 100\% de RFA, durante as quatro estações do ano. De acordo com esse autor a proporção de colmos no pré e pós-pastejo foi maior quando adotado o intervalo de pastejo com interceptação de $100 \%$ de RFA durante o verão e na média das quatro estações.

Pedreira et al. (2007), em avaliação do capim-braquiária cv. Xaraés, observaram maiores massas de colmo no póspastejo para os intervalos de pastejo com interceptação da RFA de $100 \%$ e 28 dias fixos em relação ao intervalo de pastejo com 95\% de interceptação da RFA. O efeito negativo de longos períodos de descanso sobre a estrutura do dossel forrageiro durante a estação chuvosa do ano também foi constatado nos trabalhos de Alexandrino et al. (2005), Cândido et al. (2005) e Gomide et al. (2007) em pastagens de capim-mombaça.

Os intervalos de pastejo afetaram $(\mathrm{P}<0,05)$ a composição bromatológica do capim-elefante, pois tiveram efeito nos teores de FDN, FDA, EE e MM. Não houve interação intervalo de pastejo $\times$ subperíodo $(\mathrm{P}>0,05)$ (Tabela 7).

A redução no intervalo de pastejo proporcionou menores teores de FDN e FDA no intervalo variável que no intervalo fixo de pastejo. Os teores de $\mathrm{PB}$ não diferiram entre os intervalos de pastejo $(\mathrm{P}>0,05)$. No entanto, em ambos os intervalos de pastejo, os teores de FDN obtidos foram superiores aos reportados por Vitor et al. (2009), que trabalharam com pastos de capim-elefante e encontraram

Tabela 6 - Composição morfológica do dossel forrageiro de capim-elefante manejado em intervalos de pastejo fixo ou variável

\begin{tabular}{|c|c|c|c|c|}
\hline \multirow[t]{2}{*}{ Componente } & \multicolumn{2}{|c|}{ Intervalos de pastejo } & \multirow[t]{2}{*}{$\mathrm{EPM}^{2}$} & \multirow[t]{2}{*}{$\mathrm{P}^{1}$} \\
\hline & Variável & Fixo & & \\
\hline Massa de folhas, pré-pastejo (kg de MS/ha) & 3.440 & 3.250 & 150 & 0,38 \\
\hline Massa de material morto, pré-pastejo (kg de MS/ha) & 330 & 425 & 20 & 0,008 \\
\hline Massa de folhas, pós-pastejo (kg de MS/ha) & 820 & 732 & 40 & 0,10 \\
\hline Massa de colmos, pós-pastejo (kg de MS/ha) & 2.440 & 2.720 & 120 & 0,10 \\
\hline Massa de material morto pós-pastejo (kg de MS/ha) & $300 \mathrm{a}$ & $360 \mathrm{~b}$ & 15 & 0,004 \\
\hline
\end{tabular}

Na linha, médias seguidas de diferentes letras minúsculas são diferentes a $5 \%$ de probabilidade $(\mathrm{P}<0,05)$ pelo teste Tukey.

1 Probabilidade; ${ }^{2}$ Erro-padrão da média. 
valores superiores a $73 \%$ durante a estação chuvosa do ano. Os resultados observados neste trabalho divergem dos apresentados por Deresz (2001), Deresz et al. (2001) e Wendling et al. (2004) para pastagens de capim-elefante e Cândido et al. (2005) em pastagens de capim-tanzânia, os quais não observaram efeitos dos intervalos de pastejos sobre a composição bromatológica da forragem.

Os menores teores de FDN e FDA no intervalo variável podem favorecer o consumo e a digestibilidade da forragem, respectivamente. Entretanto, de modo geral, as variações na qualidade da forragem foram pouco expressivas entre os intervalos de pastejo testados.

Os teores de PB na forragem observados neste estudo foram menores que os relatados por Santos et al. (2005). Esses autores compilaram diversos dados de composição bromatológica de gramíneas tropicais (pastejo simulado) manejadas intensivamente, em áreas experimentais e em áreas comerciais e observaram valores que variaram de 13 a $22 \%$, com grande incidência de valores superiores a $16 \%$ de $\mathrm{PB}$.

Fontaneli (2005) observou valor médio de $20 \%$ de PB em pastagens de capim-elefante (lâminas foliares) durante o verão e outono. Nesse trabalho, as pastagens foram manejadas com intervalos de pastejos de 25 a 30 dias e adubadas com $500 \mathrm{~kg}$ de N/ha.

Em condições práticas, pastagens manejadas com intervalos de pastejos menores deverão receber doses maiores de nutrientes na adubação, que aumentará os teores de nitrogênio na forragem. Johnson et al. (2001) avaliaram o efeito da adubação nitrogenada (39 a $157 \mathrm{~kg} / \mathrm{ha}$ ) em Cynodon dactylon e Cynodon nlenfuensis a cada 28 dias e observaram que os teores de nitrogênio total nas plantas aumentaram de 1,55 para 2,82\% da MS com as respectivas adubações.

Tabela 7 - Composição bromatológica de amostras de pastagens de capim-elefante manejados em intervalos de pastejo fixo ou variável

\begin{tabular}{lccr}
\hline Componente & Intervalos de pastejo & \multirow{2}{*}{$\mathrm{EPM}^{2}$} \\
\cline { 2 - 3 } & Variável & Fixo & 0,42 \\
Matéria seca (\% no alimento) & 16,58 & 16,40 & 0,28 \\
Proteína bruta (\% da MS) & 14,24 & 14,58 & 0,33 \\
Fibra em detergente neutro (\% da MS) & $65,07 \mathrm{a}$ & $66,99 \mathrm{~b}$ & 0,33 \\
Fibra em detergente ácido (\% da MS) & $35,88 \mathrm{a}$ & $37,05 \mathrm{~b}$ & 0,01 \\
Lignina (\% da MS) & 6,50 & 6,13 & 0,04 \\
Extrato etéreo (\% da MS) & $2,70 \mathrm{a}$ & $3,17 \mathrm{~b}$ & 0,23 \\
Matéria mineral (\% da MS) & $12,02 \mathrm{a}$ & $10,18 \mathrm{~b}$ & 0,07 \\
\hline
\end{tabular}

Na linha, médias seguidas de diferentes letras minúsculas são diferentes a $5 \%$ de probabilidade $(\mathrm{P}<0,05)$ pelo teste Tukey.

${ }^{1}$ Probabilidade; ${ }^{2}$ Erro-padrão da média.

\section{Conclusões}

A utilização do intervalo de pastejo variável, determinado pela condição de $95 \%$ de interceptação da radiação fotossinteticamente ativa, possibilita aplicar intervalos menores em comparação ao intervalo de pastejo fixo de 26 dias, e tem efeitos positivos na produção de forragem, no valor nutritivo da planta forrageira e na estrutura do dossel.

\section{Referências}

ALEXANDRINO, E.; GOMIDE, J.A.; GOMIDE, C.A.M. Crescimento e desenvolvimento do dossel de Panicum maxumum cv. Mombaça. Revista Brasileira de Zootecnia, v.34, n.6, p.2164-2173, 2005 (supl.).

AROEIRA, L.J.M.; LOPES, P.C.F.; SOARES, J.P.G. et al. Daily intake of lactating crossbreed cows grazing elephant grass rotationally. Pesquisa Agropecuária Brasileira, v.36, n.6, p.911-917, 2001.
ASSOCIATION OF OFFICIAL ANALYTICAL CHEMISTS - AOAC. Official methods of analysis. 12.ed. Washington, D.C.: AOAC International, 1975. 1117p.

BARBOSA, R.A.; NASCIMENTO JR., D.; EUCLIDES, V.P.B. et al. Capim Tanzânia submetido a combinações entre intensidade e freqüência de pastejo. Pesquisa Agropecuária Brasileira, v.42, p.329-340, 2007

CÂNDIDO, M.J.D.; ALEXANDRINO, E.; GOMIDE, C.A.M. et al. Período de descanso, valor nutritivo e desempenho animal em pastagens de Panicum maximum cv. Mombaça sob lotação intermitente. Revista Brasileira de Zootecnia, v.34, n.5, p.1459-1467, 2005.

CARNEVALLI, R.A.; SILVA, S.C.; BUENO, A.A.O. et al. Herbage production and grazing losses in Panicum maximum cV. Mombaça under four grazing managements. Tropical Grasslands, v.40, p.165-176, 2006.

DA SILVA, S.C. Manejo do pastejo para a obtenção de forragem de qualidade. In: SIMPÓSIO GOIANO SOBRE MANEJO E NUTRIÇÃO DE BOVINOS DE CORTE E LEITE, 7., 2005, Goiânia. Anais... Goiânia: CBNA, 2005. p.117-146.

DERESZ, F. Influência do período de descanso da pastagem de capim-elefante na produção de vacas mestiças Holandês-Zebu. Revista Brasileira de Zootecnia, v.30, n.2, p.461-469, 2001. 
DERESZ, F; LOPES, F.C.F.; AROEIRA, L.J.M. Influência de estratégias de manejo em pastagem de capim-elefante na produção de leite de vacas Holandês $\times$ Zebu. Arquivo Brasileiro de Medicina Veterinária e Zootecnia, v.53, n.4, p.1-10, 2001.

FONTANELI, R.S. Produção de leite de vacas da raça Holandesa em pastagens tropicais perenes no planalto médio do Rio Grande do Sul. 2005. 174f. Tese (Doutorado - Plantas Forrageiras) - Faculdade de Agronomia, Universidade Federal do Rio Grande do Sul, Porto Alegre.

GOERING, H.K.; VAN SOEST, P.J. Forage fiber analysis. Washington, D.C: USDA, Agricultural Research Service, 1970. (USDA, Handbook, 379), 1v.

GOMIDE, C.A.M.; GOMIDE, J.A.; ALEXANDRINO, E. Características estruturais e produção de forragem em pastos de capim mombaça submetidos a períodos de descanso. Pesquisa Agropecuária Brasileira, v.42, n.10, p.1487-1494, 2007.

JOHNSON, C.R.; REILING, B.A.; MISLEVY, P. et al. Effects of nitrogen fertilization and harvest date on yield, digestibility, fiber and protein fractions of tropical grasses. Journal of Animal Science, v.79, p.2439-2448, 2001.

MELLO, A.C.L.; PEDREIRA, C.G.S. Respostas morfofisiológicas do capim Tanzânia (Panicum maximum cv. Tanzânia-1) irrigado à intensidade de desfolha sob lotação rotacionada. Revista Brasileira de Zootecnia, v.33, p.282-289, 2004.

MORENO, L.S.B. Produção de forragem de capins do gênero Panicum e modelagem de respostas produtivas e morfofisiológicas em função de variáveis climáticas. 2004. 86f. Dissertação (Mestrado em Ciência Animal e Pastagem) - Escola Superior de Agricultura "Luiz de Queiroz"/ Universidade de São Paulo, Piracicaba.
PEDREIRA, B.C.E.; PEDREIRA, C.G.S.; SILVA, S.C. da. Estrutura do dossel e acúmulo de forragem de Brachiaria brizantha cultivar Xaraés em resposta a estratégias de pastejo. Pesquisa Agropecuária Brasileira, v.42, n.2, p.281-287, 2007.

SANTOS, F.A.P.; PEDROSO, A.M.P.; MARTINEZ, J.C. et al. Utilização da suplementação com concentrado para vacas em lactação mantidas em pastagens tropicais. In: SIMPÓSIO SOBRE BOVINOCULTURA LEITEIRA, 5., 2005, Piracicaba. Anais... Piracicaba: Fundação de Estudos Agrários Luiz de Queiroz, 2005. p.219-294.

STATISTICAL ANALYSIS SYSTEM - SAS. SAS user's guide: statistics; version 8. Cary: 1999. 965p.

VITOR, C.M.T.; FONSECA, D.M.; CÓSER, A.C. Produção de matéria seca e valor nutritivo de apstagem de capim-elefante sob irrigação e adubação nitrogenada. Revista Brasileira de Zootecnia, v.38, n.3, p.435-442, 2009.

VOLTOLINI, T.V.; SANTOS, F.A.P.; MARTINEZ, J.C. et al. Metabolizable protein supply according to the NRC (2001) for dairy cows grazing elephant grass. Scientia Agricola, v.65, n.2, p.130-138, 2008.

VOLTOLINI, T.V.; SANTOS, F.A.P.; MARTINEZ, J.C. et al. Produção e composição do leite de vacas mantidas em pastagens de capim-elefante submetidas a duas frequências de pastejo. Revista Brasileira de Zootecnia, v.39, n.1, p. 121-127, 2010.

WENDLING, I.J.; ALENCAR, C.A.B.; TEIXEIRA, S.R. et al. Produção de leite de vacas mestiças Holandês x Zebu em pastagem de capim-elefante (cv. Pioneiro) submetido a dois períodos de descanso. In: REUNIÃO ANUAL DA SOCIEDADE BRASILEIRA DE ZOOTECNIA, 41., 2004, Campo Grande. Anais... Piracicaba: SBZ, 2004. (CD-ROM). 